\title{
Congenital cholestatic syndromes: What happens when children grow up?
}

\author{
Simon C Ling MB ChB
}

\author{
SC Ling. Congenital cholestatic syndromes: What happens \\ when children grow up? Can J Gastroenterol 2007; \\ 21(11):743-751.
}

\begin{abstract}
Although advances in the management of children with congenital cholestasis have enabled many to survive into adulthood with their native livers, even the most common of these conditions remains rare in adult hepatology practice. Among four congenital cholestatic syndromes (biliary atresia, Alagille syndrome, Caroli disease and congenital hepatic fibrosis, and progressive familial intrahepatic cholestasis), the published data on outcomes of the syndromes into adulthood suggest that a spectrum of severity of liver disease can be expected, from cirrhosis (almost universal in adults with biliary atresia who have not required liver transplantation) to mild and subclinical (eg, in the previously undiagnosed affected parent of an infant with Alagille syndrome). Complications associated with portal hypertension and nutritional deficiencies are common, and other associated features of the cholestatic syndrome may require appropriate attention, such as congenital heart disease in Alagille syndrome. Indications for liver transplantation include synthetic failure, progressive encephalopathy, intractable pruritus, recurrent biliary sepsis and recurrent complications of portal hypertension. Improved understanding of biliary physiology will hopefully translate into improved therapy for children and adults with cholestasis.
\end{abstract}

Key Words: Alagille syndrome; Biliary atresia; Caroli syndrome; Children; Cholestasis; PFIC

\section{Les syndromes cholostatiques congénitaux : Que se passe-t-il lorsque l'enfant grandit?}

Bien que les progrès dans la prise en charge des enfants atteints d'une cholestase congénitale aient permis à bon nombre d'entre eux de survivre jusqu'à l'âge adulte avec leur foie d'origine, ces pathologies, même les plus courantes, demeurent rares en hépathologie pour adultes. Parmi les quatre syndromes cholostatiques congénitaux (atrésie des voies biliaires, syndrome d'alagille, maladie de Caroli et fibrose hépatique congéniale, cholestase intrahépatique héréditaire évolutive), les données publiées sur l'issue des syndromes à l'âge adulte laissent prévoir tout un spectre de gravité de maladie hépatique, en passant par la cirrhose (presque universelle chez les adultes atteints d'atrésie des voies biliaires qui n'ont pas subi de greffe hépatique) jusqu'à une maladie légère et subclinique (p. ex., chez le parent auparavant non diagnostiqué d'un nourrisson atteint du syndrome d'alagille). Les complications associées à l'hypertension portale et aux déficiences nutritionnelles sont courantes, et d'autres caractéristiques reliées au syndrome cholostatique peuvent exiger des mesures pertinentes, telles que la cardiopathie congénitale en cas de syndrome d'alagille. Les indications de greffe hépatique incluent une faille synthétique, une encéphalopathie évolutive, un prurit réfractaire, une septicémie biliaire récurrente et les complications récurrentes de l'hypertension portale. Les auteurs espèrent qu'une meilleure compréhension de la physiologie biliaire se traduira par une amélioration de la thérapie des enfants et des adultes atteints de cholestase biliaire.
$\mathrm{O}$ ver the last century, our understanding of the causes of neonatal cholestasis has grown to include infections, cholangiopathies, endocrine disorders, and increasing numbers of metabolic and genetic diseases (Table 1). At the same time, the medical and surgical management of affected children has improved, and many children with these 'pediatric diseases' now survive into adulthood and seek transfer of their care to adult hepatology services.

The present review addresses the outcomes into adulthood of these conditions and focuses on four congenital cholestatic syndromes: biliary atresia (the most common); Alagille syndrome, whose wide spectrum of severity includes previously unrecognized, mildly affected adults; the spectrum of Caroli disease and congenital hepatic fibrosis $(\mathrm{CHF})$; and progressive familial intrahepatic cholestasis (PFIC), whose investigation has enabled a greater understanding of biliary physiology with relevance to adult cholestatic liver diseases.

\section{INITIAL PRESENTATION AND INVESTIGATION OF INFANTS WITH CHOLESTATIC LIVER DISEASE}

Jaundice in the first two weeks of life is common and is mostly due to unconjugated hyperbilirubinemia that arises from a physiological delay in maturation of the bilirubin conjugation pathway or in association with breastmilk feeding. Full-term infants who remain jaundiced beyond two weeks of age require investigations to identify patients with cholestasis, in whom there is either a primary liver disease, such as biliary atresia, or a systemic disorder that affects the liver, such as hypothyroidism.

Neonatal liver disease may be present without obvious symptoms or signs other than jaundice, or may be accompanied by yellow urine (normally colourless in the newborn), pale stools, poor weight gain, pruritus, hepatosplenomegaly, ascites, edema, bruising or bleeding. Less common presentations include manifestations of hypoglycemia or coagulopathy. Some

Division of Gastroenterology, Hepatology $\mathcal{E}$ Nutrition, The Hospital for Sick Children, Toronto, Ontario

Correspondence: Dr Simon C Ling, Division of Gastroenterology, Hepatology 8 Nutrition, The Hospital for Sick Children,

555 University Avenue, Toronto, Ontario M5G 1X8. E-mail simon.ling@sickkids.ca

Received for publication April 13, 2006. Accepted January 22, 2007 
TABLE 1

The most common causes of neonatal cholestasis

\begin{tabular}{|c|c|}
\hline Cause & Type \\
\hline Idiopathic & Idiopathic neonatal hepatitis \\
\hline \multicolumn{2}{|l|}{ Bile duct obstruction } \\
\hline Cholangiopathies & $\begin{array}{l}\text { Biliary atresia, choledochal cysts, Alagille } \\
\text { syndrome, neonatal sclerosing cholangitis, } \\
\text { Caroli disease, congenital hepatic fibrosis }\end{array}$ \\
\hline Other & Gallstones or biliary sludge, inspissated bile \\
\hline \multicolumn{2}{|l|}{ Infection } \\
\hline Viral & Cytomegalovirus, human immunodeficiency virus \\
\hline Bacterial \& parasitic & Urinary tract infection, bacterial sepsis, syphilis \\
\hline \multicolumn{2}{|c|}{ Genetic, metabolic and endocrine disorders } \\
\hline Metabolic & $\begin{array}{l}\text { Alpha-1-antitrypsin deficiency, cystic fibrosis, } \\
\text { tyrosinemia, galactosemia, progressive familial } \\
\text { intrahepatic cholestasis }\end{array}$ \\
\hline Endocrine & Hypothyroidism, panhypopituitarism \\
\hline Toxicities & Parenteral nutrition, drugs \\
\hline
\end{tabular}

Data from reference 1

causes of neonatal liver disease have specific associated abnormalities, such as skin lesions and choroidoretinitis in patients with congenital infections by cytomegalovirus or toxoplasma, cataracts in galactosemia patients and congenital heart disease in patients with Alagille syndrome.

The initial investigation of infants with liver disease focuses on the identification of conditions that require urgent management, including associated abnormalities such as coagulopathy, hypoglycemia and fat-soluble vitamin deficiencies. Occasionally, a cholestatic infant may appear acutely unwell or show evidence of liver failure; this requires significant supportive care and urgent investigation for the underlying cause, which may include infection (eg, urinary tract infection, bacterial septicemia or enterovirus infection), metabolic disease (eg, galactosemia or tyrosinemia), panhypopituitarism, neonatal hemochromatosis or acute common bile duct obstruction. Most infants with neonatal cholestasis are not so unwell and may appear misleadingly healthy. Those infants' investigations begin with a review of neonatal screening for hypothyroidism and galactosemia, urine culture, characterization of standard hematological and liver parameters with bloodwork, measurement of alpha-1-antitrypsin level or phenotype and abdominal ultrasound (US). The diagnosis of biliary atresia cannot be made reliably with an US scan, although an absent or atretic gallbladder is suggestive of biliary atresia. Therefore, if the cause of liver disease remains unclear after those initial tests, a nuclear medicine biliary excretion scan and/or a percutaneous liver biopsy are performed. Percutaneous cholangiogram may also be attempted. Infants whose investigation reveals likely biliary obstruction are referred for surgery. Further medical evaluation is performed in those without evidence of biliary obstruction to identify other infectious, metabolic or genetic disorders (1).

\section{BILIARY ATRESIA}

Approximately one in 14,000 live births is affected by biliary atresia, which is one of the most common causes of neonatal cholestasis. It is characterized by fibroinflammatory obliteration of the lumen of all or part of the extrahepatic biliary tree, intrahepatic inflammation and progressive fibrosis, and it is

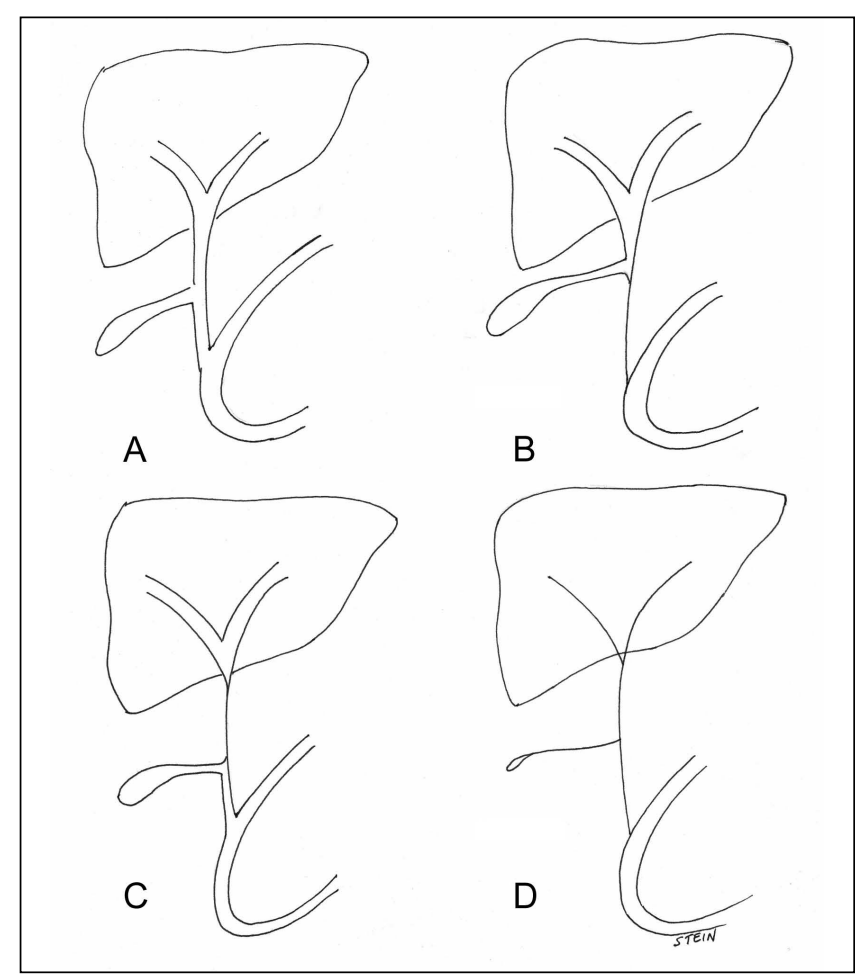

Figure 1) Classification of biliary atresia according to the extent of involvement of the biliary tree. A Normal. B Type 1; atresia of the common bile duct. C Type 2; atresia of the common hepatic duct. D Type 3, atresia of the entire extrahepatic biliary tree

associated with other significant congenital anomalies in $10 \%$ to $20 \%$ of affected children. Atresia may affect the common bile duct (type 1), the common hepatic duct (type 2) or the entire exptrahepatic biliary tree to the level of the porta hepatis (type 3 , which is the most common type) (Figure 1).

The cause of biliary atresia is unknown. Current research efforts (2) are exploring evidence that perinatal infection (eg, with reovirus or rotavirus) may interact with as yet undefined genetic factors that influence the inflammatory response and the presence of associated malformations. A minority of affected infants exhibit associated abnormalities, such as congenital heart disease, that develop early in gestation and therefore suggest an 'embryonic' subtype of biliary atresia. Infants without associated anomalies are presumed to have suffered a late gestational or early postnatal insult (the 'perinatal' subtype) (2). Differences in gene expression profiles in these two subtypes of biliary atresia have been described (3), but the validity of this classification remains unclear while proof of timing of etiological insult is sought, due to evidence that biliary atresia without associated anomalies may develop early in gestation $(4,5)$.

\section{Surgical management of biliary atresia}

Biliary atresia is uniformly fatal within one to two years if left untreated. Initial attempts at surgical management are undertaken in most cases. At laparotomy, the diagnosis of biliary atresia is confirmed by direct inspection of the extrahepatic biliary tree and intraoperative cholangiography. The fibrous remnant of the common bile duct is transected above the duodenal margin, and then the remnants of the common bile duct, cystic duct, gallbladder and common hepatic duct are dissected 
TABLE 2

Characteristics of 63 adults with biliary atresia surviving with their native liver

\begin{tabular}{lc}
\hline Complication & Patients, n (\%) \\
\hline Cirrhosis & $61(97)$ \\
Portal hypertension & $44(70)$ \\
Gastrointestinal bleeding & $20(32)$ \\
Total bilirubin level >17 $\mu \mathrm{mol} / \mathrm{L}$ & $42(67)$ \\
Coagulopathy & $19(30)$ \\
Late bacterial cholangitis (17 to 30 years old) & $19(30)$ \\
Gallstones & $6(10)$
\end{tabular}

Data from reference 17

to identify their location anterior and superior to the bifurcation of the portal vein, where they enter a fibrous plate at the porta hepatis. This fibrous plate is dissected and transected at the level of the liver capsule, exposing a cut surface of hepatic parenchyma beneath. Roux-en-Y drainage is then fashioned using a limb of proximal jejunum anastamosed over the exposed hilar parenchyma. This operation has been known as the Kasai portoenterostomy since its original description by Kasai and Suzuki in 1957, and is reviewed in more detail elsewhere (6). Interest in laparoscopic portoenterostomy has increased following early reports of improved visualization of the surgical field and successful outcomes (7).

Most centres report successful re-establishment of bile flow and clearance of jaundice in 50\% to $60 \%$ of infants who undergo the Kasai portoenterostomy. Large reported series (8-11) from Europe and North America reveal medium-term survival without liver transplantation in $25 \%$ to $60 \%$ of patients after two to 10 years of follow-up examinations. A good patient outcome has been associated with early age (younger than 60 days) and the absence of cirrhosis at the time of Kasai portoenterostomy, fewer episodes of cholangitis following surgery and the longterm maintenance of good nutritional status (10,12-14). Success may depend in part on the experience of the surgeon or centre $(15,16)$. Postoperative complications include recurrent cholangitis, which is most common in the early months after surgery, and manifestations of portal hypertension, including variceal hemorrhage.

\section{Liver transplantation for patients with biliary atresia}

Liver transplantation is required for children who fail to clear jaundice after surgery. In addition, many children in whom surgery is successful develop progressive liver disease despite adequate postoperative bile flow. Overall, only a minority of children diagnosed with biliary atresia survive into adulthood without liver transplantation.

Indications for liver transplantation include liver synthetic failure, uncontrollable complications of portal hypertension, frequently recurrent cholangitis and a profound failure to thrive. Biliary atresia is the most common reason for liver transplantation in childhood.

Outcome and management of biliary atresia in adulthood In Paris, 63 of 271 children (23\%) diagnosed with biliary atresia survived 20 years without transplantation, and their clinical condition after that long-term follow-up period was recently described (17) (Table 2 ). Nearly all patients were cirrhotic, two-thirds showed evidence of portal hypertension and

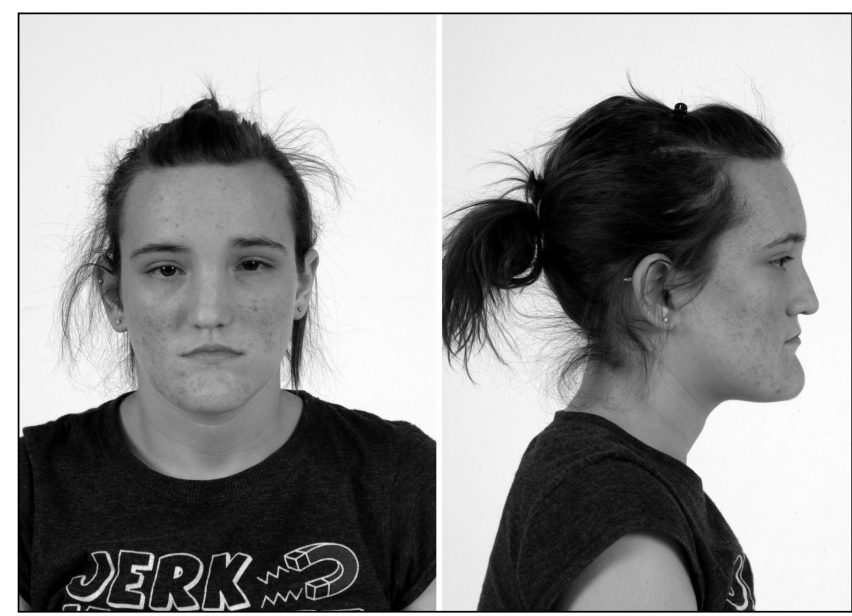

Figure 2) A 16-year-old girl with Alagille syndrome (reproduced with the patient's permission)

one-third had suffered gastrointestinal bleeding. Cholangitis continued to be a problem in approximately one-third of those patients, even at ages between 17 and 30 years. The authors concluded that many of the patients had a good quality of life; they had regular employment or university education, they were married or in stable relationships, and seven women and two men were parents to a total of 11 children. Six patients suffered from depression, three of whom consumed excess alcohol.

Level 1 evidence to guide treatment choices in the postoperative follow-up of children and adolescents with biliary atresia is scarce, and recommendations for the management of young adults therefore rely mostly on extrapolation of pediatric clinical experience. Nutrition support and fat-soluble vitamin supplementation may be required in patients with significant cholestasis, impaired appetite and nutrient malabsorption (18). Antibiotic prophylaxis against cholangitis is recommended, although there is only poor evidence for its efficacy $(19,20)$. The risk of infection appears to be increased in patients with intrahepatic bile lakes or cysts, which represent areas of tissue breakdown where infection may linger during antibiotic therapy (21). Ursodeoxycholic acid is commonly administered to improve bile flow and protect the liver against the toxic effects of cholestasis, although studies of its efficacy in biliary atresia are lacking. Most pediatric hepatologists do not routinely undertake primary prophylaxis against gastrointestinal variceal hemorrhage for reasons that have been previously reviewed (22). However, as pediatric patients approach adulthood, standard adult recommendations for the management of portal hypertension should be adopted (23). Referral for liver transplantation should occur when the usual listing criteria are met, including the onset of liver synthetic failure and the presence of uncontrollable complications of portal hypertension. In addition, transplantation is an appropriate treatment for multiple recurrent or persistent episodes of cholangitis.

\section{ALAGILLE SYNDROME}

Described in 1969 by Daniel Alagille (24), the diagnosis of his eponymous syndrome relies on the identification of characteristic clinical features, including typical facies (Figure 2), cholestasis with intrahepatic bile duct paucity identified by liver biopsy, heart murmur caused by peripheral pulmonary artery 


\section{TABLE 3}

Manifestations of Alagille syndrome

\begin{tabular}{|c|c|}
\hline Location & Manifestations \\
\hline Face & Typical subtle dysmorphic features \\
\hline Cardiac & $\begin{array}{l}\text { Peripheral pulmonary artery stenosis, tetralogy of Fallot, } \\
\text { other intracardiac disease, hypertension }\end{array}$ \\
\hline Renal & $\begin{array}{l}\text { Dysplastic kidneys, multicystic kidneys, solitary kidney, } \\
\text { ectopic kidney, horseshoe kidney, renal tubular acidosis, } \\
\text { glomerular lipidosis, bifid renal pelvis, renal artery } \\
\text { stenosis, adult-onset renal failure }\end{array}$ \\
\hline Skeletal & $\begin{array}{l}\text { Short stature, butterfly vertebrae, hemivertebrae, metabolic } \\
\text { bone disease, rickets, recurrent fractures }\end{array}$ \\
\hline Vascular & $\begin{array}{l}\text { Progressive cerebral artery stenosis ('moya-moya } \\
\text { disease'), renal artery stenosis, stenosis of the } \\
\text { abdominal aorta ('mid-aortic syndrome') }\end{array}$ \\
\hline Ocular & Posterior embryotoxon, xanthelasma \\
\hline Hepatic & $\begin{array}{l}\text { Paucity of the intrahepatic bile ducts, extrahepatic biliary } \\
\text { hypoplasia, hepatocellular carcinoma }\end{array}$ \\
\hline Dermatological & Severe pruritus, xanthoma formation \\
\hline Neurological & $\begin{array}{l}\text { Intracranial hemorrhage (epidural, subdural, subarachnoid, } \\
\text { intraparenchymal) }\end{array}$ \\
\hline
\end{tabular}

stenosis or other congenital heart disease, sagittal cleft ('butterfly') vertebrae, ocular abnormalities such as posterior embryotoxon and renal abnormalities including multicystic or dysplastic kidneys $(24,25)$. The severity of these clinical manifestations is variable. More severe, intra-cardiac congenital heart anomalies occur in $25 \%$ of patients (of which tetralogy of Fallot is the most common) and are the main cause of poor outcomes early in life; in one series of 92 children with Alagille syndrome reported in 1999 (26), survival to six years of age was reduced from $95 \%$ to $40 \%$ by the presence of intracardiac congenital heart disease.

The development of cirrhosis and portal hypertension becomes a more frequent and severe clinical problem with longer survival, although many children continue with only mild liver disease. The rare development of hepatocellular carcinoma has been reported in several case reports (27), introducing the possibility that these patients may be at greater risk of developing this tumour than other young patients with chronic liver disease. Overall $21 \%$ to $31 \%$ of patients require liver transplantation during childhood, including approximately $50 \%$ of those diagnosed in infancy $(26,28)$.

Other adverse outcomes arise from the numerous extrahepatic associated features of this syndrome (Table 3). For example, renal artery stenosis with associated hypertension, and adult-onset renal failure requiring kidney transplantation have been reported $(29,30)$. Intracranial hemorrhage may affect up to $15 \%$ of children with Alagille syndrome, and $30 \%$ to $50 \%$ of those events are fatal $(26,28)$. Minor head trauma often precedes bleeding, which usually occurs without coagulopathy, and its location is variable; epidural, subdural, subarachnoid and intraparenchymal bleeding have all been reported. The risk of bleeding is postulated to arise from pre-existing abnormalities of the intracranial vasculature, including stenoses and aneurysms of the carotid and cerebral arteries (31). Vascular abnormalities have also been reported elsewhere, including aortic aneurysm and coarctation (32).

\section{Genetics of Alagille syndrome}

The investigation of relatives of proband cases reveals that the previous clinical definition of Alagille syndrome may be too narrow. Alagille syndrome is an autosomal dominant disease that arises from mutations in the Jagged1 (JAG1) gene, which encodes a ligand for Notch receptors $(33,34)$. The Notch signalling pathway regulates proliferation and differentiation of a variety of cell types during development. Defects in the pathway are associated with embryonic angiogenic abnormalities and are presumed to impair bile duct formation in Alagille syndrome, although its exact function in liver and biliary tree development is unknown (35).

\section{Alagille syndrome in adults}

When relatives of 34 patients with Alagille syndrome were screened (36), 30 parents, 16 siblings and seven other relatives were identified to have the same JAG1 mutation as their proband case, and were subsequently investigated for features of Alagille syndrome. Of those relatives, $21 \%$ clearly met the diagnostic criteria for Alagille syndrome (ie, liver disease associated with three of cardiac, renal, ocular, vertebral or facial features) and 32\% met the diagnostic criteria when tested. Four per cent of the relatives had no clinical features and $43 \%$ showed only one or two features. Therefore, it seems likely that patients with Alagille syndrome, according to accepted clinical criteria, form only part of a broad spectrum of this disorder, which includes other people with JAG1 gene mutations but partial and often asymptomatic expression of the syndrome's clinical features.

Management of the young adult with Alagille syndrome is focused on nutritional support, including fat-soluble vitamin supplementation and enteral tube feeds when necessary (37). Ursodeoxycholic acid is used to improve bile flow and protect against the toxic effects of cholestasis. Cholestyramine may reduce xanthoma formation and, along with rifampin, alleviates troublesome pruritus. If these agents fail, partial external biliary diversion reduces pruritus in the majority of children in whom it has been attempted, although the effect has been only temporary in some (38). Monitoring should include blood pressure and urinalysis to identify evolving renal disease. Hypercholesterolemia is a common finding, but its implications for long-term cardiovascular health in adults with Alagille syndrome have not been quantified. Genetic counselling should be offered to patients who are planning their own family.

Indications for liver transplantation include cirrhosis with failing hepatic synthetic function and profound failure to thrive unresponsive to enteral nutritional support. Intractable pruritus resistant to conservative management is often improved by biliary diversion surgery and is therefore now a less common reason for transplantation. The decision to list for transplant must take into consideration its effect on outcome of associated abnormalities, including congenital cardiovascular disease and renal disease. Deaths due to postoperative complications of cardiovascular disease reduce overall survival rates, although cases of successful outcomes in children with severe heart disease have been reported (39-41). Because Alagille syndrome has autosomal dominant inheritance and its clinical manifestations may be unrecognized, careful evaluation of potential donors for living-related transplantation is required to ensure that covert bile duct paucity is recognized and to minimize the risk of donor surgery (42). 
TABLE 4

Syndromes associated with congenital hepatic fibrosis and Caroli syndrome

Autosomal recessive polycystic kidney disease
Autosomal dominant polycystic kidney disease
Autosomal dominant polycystic liver disease
Nephronophthisis type 3
Jeune syndrome
Joubert syndrome
Meckel-Gruber syndrome
Bardet-Biedl syndrome
Ivemark syndrome
Congenital disorder of glycosylation type 1b

\section{CAROLI DISEASE AND CHF}

Among the several hepatic fibrocystic syndromes (Table 4), liver disease associated with autosomal recessive polycystic kidney disease (ARPKD) is the most commonly recognized in children. Affecting one in 20,000 infants, ARPKD usually presents either with manifestations of renal disease (including hematuria, hypertension, growth retardation and renal failure), or following the coincidental finding of nephromegaly on antenatal or postnatal US scans (43). Renal disease may be severe and life-threatening in infancy, whereas liver disease typically develops later in childhood in survivors, although some affected infants have neonatal cholestasis.

Genetics and pathogenesis of $\mathrm{CHF}$ and Caroli syndrome ARPKD is caused by mutations in the PKHD1 gene, which encodes the protein fibrocystin (44). This protein has been localized to cilia on cholangiocytes and renal collecting duct epithelial cells, and is thought to be a receptor protein important in biliary and collecting duct differentiation (45). In the liver, the development of bile ducts and portal veins is closely associated. Portal vein radicals are each initially surrounded along their length by progenitors of biliary cells, ie, the ductal plate. As development proceeds, controlled proliferation and apoptosis enables longitudinal areas of this ductal plate to form tubes that become intrahepatic bile ducts, while the remaining ductal plate involutes (Figure 3) (46). An abnormality of this process in $\mathrm{CHF}$ and Caroli syndrome results in incomplete bile duct maturation and the appearance of ductal plate malformation when liver biopsy is performed (Figure 4).

\section{Liver disease in patients with ARPKD}

The spectrum of liver disease associated with ARPKD involves fibrosis associated with abnormalities of the biliary tree, including bile ductular hypoplasia, ectasia and dysgenesis. Patients whose predominant hepatic manifestation is liver fibrosis with little evidence of cystic intrahepatic biliary dilations by diagnostic imaging are said to have CHF. If bile duct abnormalities are prominent, then diagnoses are described as Caroli disease (in which there is no fibrosis) or Caroli syndrome (combined bile duct dilations and $\mathrm{CHF}$ ).

Liver disease affects between $15 \%$ and $45 \%$ of children with ARPKD, and typically presents after infancy with features of portal hypertension, including splenomegaly and variceal hemorrhage (43). Jaundice and pruritus are only rarely present in infancy. Findings on clinical examination include hepatomegaly, splenomegaly and palpable kidneys. Patients

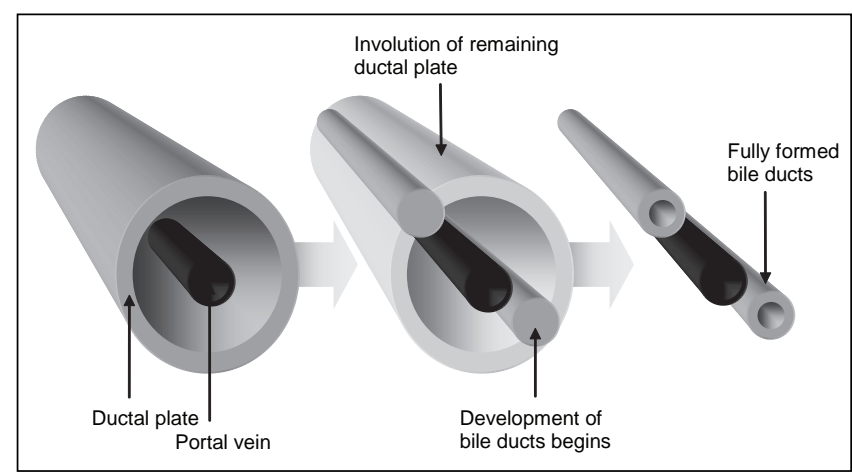

Figure 3) Embryological development of bile ducts from the ductal plate

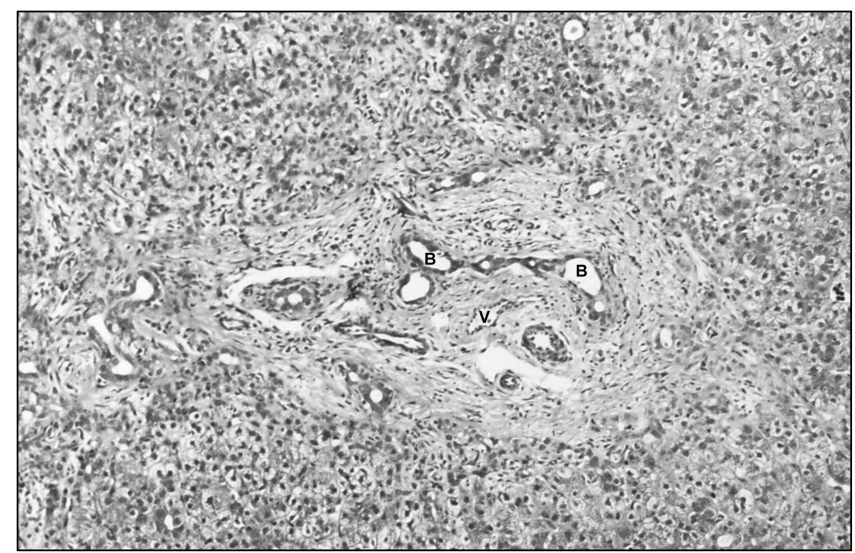

Figure 4) Ductal plate malformation, showing abnormally formed bile ducts (B) around a portal vein radical (V) in a portal triad expanded by fibrosis. The trichrome stain was supplied by Dr I Wanless, Department of Pathology, Dalhousie University (Halifax, Nova Scotia)

with Caroli syndrome are at risk of developing ductal lithiasis and bacterial cholangitis, as well as the complications of portal hypertension. Hepatic synthetic function is usually wellmaintained throughout childhood, although liver failure may occur following recurrent cholangitis.

The diagnosis of CHF or Caroli syndrome should be considered in a child with ARPKD or other associated syndromes in whom elevation of liver enzymes, hepatic abnormality identified by US scan or splenomegaly is noted. When typical cystic bile duct abnormalities are identified by US, computed tomography or magnetic resonance imaging scan in this clinical setting, further diagnostic evaluation may be unnecessary. However, liver biopsy may be required in patients without bile duct abnormality seen by diagnostic imaging, in patients whose renal disease is uncertain or if the possibility of other differential diagnoses would otherwise remain high, such as primary sclerosing cholangitis in patients presenting with significant cholestasis. Liver biopsy can reveal a variable degree of fibrosis, although it is often severe, and biliary abnormalities that include dilation and irregular contour consistent with ductal plate malformation (Figure 4) (46).

The largest published series of children with ARPKD presented data from a North American registry (47), which divided 209 patients into younger and older groups according to the time of their presentation, either before or after 1990. Among the 166 younger children, hepatic complications included portal hypertension (15\%) and variceal bleeding (4\%). 
Cholangitis occurred in $4 \%$ of the younger children and correlated with the presence of dilated bile ducts. Liver transplantation was required in only four of these 166 children (2\%). The risk of death was determined primarily by the presence of respiratory insufficiency in the first month of life and chronic renal insufficiency. Overall, survival rates were $86 \%$ at the age of one month, $79 \%$ at the age of one year and $75 \%$ at the age of five years. Of those patients who survived their first month, $87 \%$ were still alive at five years of age.

Among 43 older patients with ARPKD in the North American registry (47), portal hypertension was present in 14 patients (34\%) and four patients (11\%) had suffered variceal hemorrhage. Three children (7\%) had undergone liver transplantation, confirming the usual long-term maintenance of hepatic synthetic function.

\section{CHF and Caroli syndrome in adults}

Few reports have been published of the long-term outcomes into adulthood of patients with ARPKD. Recently, 16 consecutive adult patients with ARPKD presenting to nephrologists in Europe were described (48). Liver disease had been present at the time of diagnosis of ARPKD during childhood in seven patients and had developed subsequently (but before 18 years of age) in another four patients. Bloodwork showed normal liver enzymes in all patients. Two patients had dilation of intrahepatic bile ducts identified by diagnostic imaging. One of those patients had suffered recurrent cholangitis and one patient had developed cholangiocarcinoma at 47 years of age. Portal hypertension was present in six patients, five of whom had suffered variceal hemorrhage. At a mean age of 27 years (range 18 to 55 years), one patient had died as the result of cholangiocarcinoma and gastrointestinal bleeding, two patients had received a renal transplantation, one patient received regular renal dialysis, and 11 patients had chronic renal insufficiency.

In a retrospective review (49) of 65 patients with ARPKD or isolated CHF presenting to the Mayo Clinic (Rochester, Minnesota, USA), the large majority of older children and adults presented with hepatomegaly, splenomegaly, gastrointestinal bleeding or cholangitis. Occasionally, adults were identified during investigation with hypertension, abdominal mass, urinary tract infection, kidney stones or flank pain. Among 20 patients who were diagnosed after 20 years of age and followed for a mean of 10 years, six had isolated CHF without apparent renal disease, five had had esophageal variceal hemorrhage requiring endoscopic therapy or creation of a portal-systemic shunt, and five had had episodes of cholangitis. Liver transplantation was not required in any patient diagnosed in adulthood, but was required in four of 16 patients diagnosed between one and 20 years of age. Six adult patients died between 24 and 76 years of age; one died from cholangiocarcinoma, one died from sepsis and four died from unknown causes.

\section{Management of $\mathrm{CHF}$ and Caroli syndrome in adults}

Among older patients with CHF and Caroli syndrome, the management of portal hypertension and its complications is the greatest clinical challenge. Although this liver disease differs from cirrhosis, guidelines for the management of cirrhotic portal hypertension are commonly applied. To enable primary prophylaxis of variceal hemorrhage, screening endoscopy may be undertaken in patients with splenomegaly, thrombocytopenia or abdominal imaging suggesting significant portal hypertension to identify those patients with large varices. However, the efficacy of nonselective beta-blockers for the primary prevention of variceal hemorrhage has only been demonstrated in patients with cirrhosis. Their use in this noncirrhotic disease is unproven. Endoscopic variceal ligation is commonly performed for the management of varices in patients with CHF or Caroli syndrome who present with variceal hemorrhage. In cases of recurrent bleeding in spite of endoscopic and/or medical therapy, portal-systemic shunting should be considered (23).

Cholangitis occurring in patients with cystic biliary dilations is diagnosed by the usual clinical criteria. Blood cultures may occasionally identify the causative organism. If blood cultures are negative, image-guided aspiration of a biliary cyst may be helpful in cases of recurrent or persistent cholangitis in spite of apparently adequate antibiotic therapy. When recurrent cholangitis occurs in bile cysts that are limited to a focal area of the liver, such as the left lobe, surgical excision has been advocated (50).

Liver transplantation is reserved for rare patients with liver synthetic failure, sometimes secondary to recurrent cholangitis, or if problems from portal hypertension persist in spite of optimal medical management and portal-systemic shunting. The effects of liver transplantation and subsequent long-term immunosuppressant medications on renal function must be carefully weighed with the help of a nephrologist, and consideration should be given to combined liver and kidney transplantation if the predicted risk of post-transplant renal failure is high.

Similarly, patients with Caroli syndrome or CHF who require renal transplantation must be assessed by a hepatologist in an attempt to determine the likelihood of significant liver disease arising after transplantation. Overall survival following renal transplantation is not significantly affected by the presence of Caroli syndrome or CHF, although sepsis may be more common $(51,52)$. Occasionally, patients may suffer severe complications related to their liver disease, including ascending cholangitis and liver failure $(51,52)$. Factors predictive of hepatic decompensation after renal transplantation for ARPKD have not been systematically studied.

\section{PFIC}

In 1969, a group of seven children from Baltimore were described (53), each of whom had presented in mid-infancy with jaundice, loose, foul stools and growth failure. Four of the children had died between four and six years of age, and three were still alive at the time of the report, between the ages of 13 and 15 years. The children were all from Amish communities, and their family history revealed common ancestry over six or seven generations, ie, all had descended from Jacob and Nancy Byler, the great-grandchildren of some of the first Amish immigrants (54). Their cholestatic liver disease was named Byler disease, which was later defined as one of three types of PFIC (Table 5). These three PFIC phenotypes are caused by mutations in three different genes: FIC1 (or ATP8B1) for PFIC type 1, BSEP (or ABCB11) for PFIC type 2 and MDR3 (or ABCB4) for PFIC type 3 (Figure 5).

\section{Clinical presentation and course of PFIC}

Children with PFIC usually present in infancy with jaundice and marked pruritus. Poor weight gain and clinical evidence of specific fat-soluble vitamin deficiency may be apparent. 
TABLE 5

Characteristics of persistent familial intrahepatic cholestasis (PFIC) and associated cholestatic disorders

\begin{tabular}{|c|c|c|c|}
\hline PFIC type & Characteristics in children & Associated diseases & Gene \\
\hline $\begin{array}{l}\text { PFIC type } 1 \\
\text { (Byler disease) }\end{array}$ & $\begin{array}{l}\text { - Jaundice, pruritus } \\
\text { - Extrahepatic features (eg, diarrhea, pancreatitis, renal disease, hearing loss) } \\
\text { - Normal gamma-glutamyl transferase levels } \\
\text { - Biopsy showing bland cholestasis and coarse granular bile when examined } \\
\text { through an electron microscope }\end{array}$ & $\begin{array}{l}\text { Benign recurrent intrahepatic } \\
\text { cholestasis type } 1\end{array}$ & FIC1 (ATP8B1) \\
\hline PFIC type 2 & $\begin{array}{l}\text { - Jaundice, pruritus, occasionally liver failure } \\
\text { - No extrahepatic features } \\
\text { - Normal gamma-glutamyl transferase levels } \\
\text { - Biopsy showing bile duct proliferation, giant cell transformation, fibrosis, amorphous } \\
\text { bile when examined through an electron microscope }\end{array}$ & $\begin{array}{l}\text { Benign recurrent intrahepatic } \\
\text { cholestasis type } 2\end{array}$ & $B S E P(A B C B 11)$ \\
\hline PFIC type 3 & $\begin{array}{l}\text { - Jaundice, pruritus, cholelithiasis } \\
\text { - No extrahepatic features } \\
\text { - High gamma-glutamyl transferase levels } \\
\text { - Biopsy showing bile duct proliferation and inflammation }\end{array}$ & $\begin{array}{l}\text { Intrahepatic cholestasis } \\
\text { of pregnancy } \\
\text { Cholelithiasis }\end{array}$ & MDR3 (ABCB4) \\
\hline
\end{tabular}

Evidence of chronic hepatitis or cirrhosis may be present. Associated extrahepatic problems, including renal dysfunction, pancreatitis and hearing loss, suggest PFIC type 1. Diagnosis of PFIC may be challenging. Identification of a genetic mutation is clearly helpful, but this analysis is not yet readily available in clinical practice. Other supportive test results may help to distinguish the likelihood of each PFIC type.

Unlike other forms of cholestatic liver disease, PFIC type 1 and PFIC type 2 are characterized by a normal or minimally elevated circulating concentration of gamma-glutamyl transferase (GGT). The detergent effect of bile acids normally enables the elution of GGT from the canalicular membrane into bile. During cholestasis, GGT refluxes from canalicular bile into the plasma, and thus, its circulating concentration increases. Bile that lacks bile acids due to a transport molecule or synthetic defect is an inefficient detergent, and is thus associated with a low biliary GGT concentration and a low plasma GGT, even during cholestasis. Both PFIC type 1 and PFIC type 2 are associated with bile acid-deficient bile and, therefore, low plasma GGT $(55,56)$. The workup of infants presenting with cholestasis and pruritus but without elevation of GGT should therefore include investigation for evidence of PFIC type 1 or PFIC type 2. PFIC type 3 should be considered in infants with persistent jaundice, pruritus and elevated GGT in whom no other cause has been identified.

Liver biopsy may show 'bland' cholestasis in PFIC type 1, in which marked cholestasis contrasts with a lack of inflammatory or other changes and coarse, granular bile may be seen in the bile canaliculi on electron microscopy. Inflammation, giant cell transformation and early fibrosis are more commonly seen in PFIC type 2.

Outcome and management of PFIC

There is limited information on the long-term outcomes of PFIC into adulthood, although some medium-term data in children are available. In one report (57) of 33 children with PFIC of unspecified types (all with low GGT), seven were 16 years of age or older at the time of their last follow-up visit. Five of the seven children were below the fifth percentile for height, six children had significant pruritus, two children had suffered rickets and vitamin E neuropathy and five children

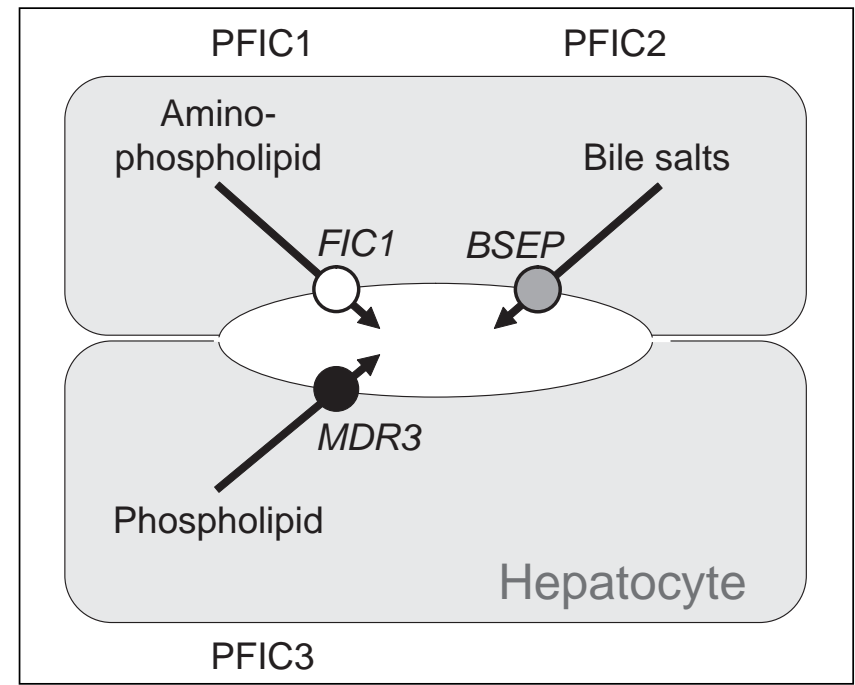

Figure 5) Canalicular transport molecules involved in the three types of persistent familial intrahepatic cholestasis (PFIC). BSEP Bile salt export pump (now called ABCB11); FIC1 Familial intrahepatic cholestasis 1 (now called ATP8B1); MDR3 Multi-drug resistance protein type 3 (now called ABCB4)

had gallstones. More recently, a report (58) that described 10 children with PFIC type 2 suggested that this disease is a significant risk factor for the development of hepatocellular carcinoma.

Medical management of pruritus in PFIC with ursodeoxycholic acid, cholestyramine and rifampin is often inadequate to control this troublesome symptom. Little benefit has been gained from therapeutic trials of other therapies, including opioid antagonists, antihistamines and ondansetron. Partial external biliary diversion offers relief to many children who undergo this procedure, although some experience only transient benefit (59). Liver transplantation is offered to children with the standard indications, as well as those with intractable pruritus (60). The use of live, related liver donors who are likely to be heterozygous for the disease-causing gene does not appear to compromise outcomes (61). 


\section{Liver diseases related to PFIC that affect adults}

Some patients with benign recurrent intrahepatic cholestasis (BRIC) have phenotypic similarities to PFIC type 1, including diarrhea and recurrent pancreatitis, and also demonstrate mutations in FIC1 (62). Patients with BRIC and BSEP mutations have been described as BRIC type 2, which is associated with an increased incidence of cholelithiasis (63).

Intrahepatic cholestasis of pregnancy occurs in $1 \%$ of pregnancies and is associated with sudden, unexplained fetal death in up to $3.5 \%$, and its outcome is improved by treatment with ursodeoxycholic acid; GGT is elevated in a minority of cases, and cholelithiasis is common (64). Genetic susceptibility has been suggested by familial clustering and the observation of a much higher prevalence among certain ethnic groups, including the Araucanos Indians in Chile (65). Mutations in the MDR3 gene, responsible for PFIC type 3 , have been found in up to $15 \%$ of cases with intrahepatic cholestasis of pregnancy, especially those with elevated GGT and/or cholelithiasis (66). MDR3 gene mutations have also been associated with cholelithiasis and cirrhosis presenting in adults (67-69).

\section{REFERENCES}

1. Moyer V, Freese DK, Whitington PF, et al. Guideline for the evaluation of cholestatic jaundice in infants: Recommendations of the North American Society for Pediatric Gastroenterology, Hepatology and Nutrition. J Pediatr Gastroenterol Nutr 2004;39:115-28. (Erratum in 2004;39:306).

2. Mack CL, Sokol RJ. Unraveling the pathogenesis and etiology of biliary atresia. Pediatr Res 2005;57:87R-94R.

3. Zhang DY, Sabla G, Shivakumar P, et al. Coordinate expression of regulatory genes differentiates embryonic and perinatal forms of biliary atresia. Hepatology 2004;39:954-62.

4. Davenport M. A challenge on the use of the words embryonic and perinatal in the context of biliary atresia. Hepatology 2005;41:403-4

5. Muise AM, Turner D, Wine E, Kim P, Marcon M, Ling SC. Biliary atresia with choledochal cyst: Implications for classification. Clin Gastroenterol Hepatol 2006;4:1411-4.

6. Balistreri WF, Bezerra JA, Ryckman FC. Biliary atresia and other disorders of the extrahepatic bile ducts. In: Suchy FJ, Sokol RJ, Balistreri WF, eds. Liver Disease in Children. Philadelphia: Lippincott Williams \& Wilkins, 2001:253-74.

7. Aspelund G, Ling SC, Ng V, Kim PC. A role for laparoscopic approach in treatment of biliary atresia and choledochal cysts. J Pediatr Surg 2007;42:869-72.

8. Schreiber RA, Barker C, Roberts EA, Martin SR, Smith L. Neonatal biliary atresia: The Canadian experience, 1985-2002. Hepatology 2005;42(Suppl 1):367A. (Abst)

9. Chardot C, Carton M, Spire-Bendelac N, Le Pommelet C, Golmard JL, Auvert B. Prognosis of biliary atresia in the era of liver transplantation: French national study from 1986 to 1996. Hepatology 1999;30:606-11.

10. Wildhaber BE, Coran AG, Drongowski RA, et al. The Kasai portoenterostomy for biliary atresia: A review of a 27-year experience with 81 patients. J Pediatr Surg 2003;38:1480-5.

11. Shneider BL, Brown MB, Haber B, et al. A multicenter study of the outcome of biliary atresia in the United States, 1997 to 2000. J Pediatr 2006;148:467-74.

12. Utterson EC, Shepherd RW, Sokol RJ, et al. Biliary atresia: Clinical profiles, risk factors, and outcomes of 755 patients listed for liver transplantation. J Pediatr 2005;147:180-5.

13. Shteyer E, Ramm GA, Xu C, White FV, Shepherd RW. Outcome after portoenterostomy in biliary atresia: Pivotal role of degree of liver fibrosis and intensity of stellate cell activation. J Pediatr Gastroenterol Nutr 2006;42:93-9.

14. Kobayashi A, Itabashi F, Ohbe Y. Long-term prognosis in biliary atresia after hepatic portoenterostomy: Analysis of 35 patients who survived beyond 5 years of age. J Pediatr 1984;105:243-6.

15. McKiernan PJ, Baker AJ, Kelly DA. The frequency and outcome of biliary atresia in the UK and Ireland. Lancet 2000;355:25-9.
Our improved knowledge of bile salt physiology gained through investigation of PFIC kindreds is now being applied to the search for a better understanding of other more common cholestatic disorders, such as primary sclerosing cholangitis and primary biliary cirrhosis. However, an initial study (70) of this question yielded negative results, suggesting no involvement of mutations in BSEP or MDR3 in the pathogenesis of these more common cholestatic diseases.

\section{SUMMARY}

The boundaries between pediatric and adult cholestatic liver diseases have been blurred by the survival into adulthood of children with congenital cholestatic syndromes; by the identification of 'adult disease' such as primary biliary cirrhosis in children (71); and by the discovery of common genetic bases for PFIC, BRIC, cholelithiasis and intrahepatic cholestasis of pregnancy. Treatment options are limited for patients of any age with these disorders, and we must therefore continue to focus on translating the evolving knowledge of biliary physiology into the discovery of new and more effective therapies for the benefit of both children and adults.

16. Serinet MO, Broue $\mathrm{P}$, Jacquemin E, et al. Management of patients with biliary atresia in France: results of a decentralized policy 1986-2002. Hepatology 2006;44:75-84.

17. Lykavieris P, Chardot C, Sokhn M, Gauthier F, Valayer J, Bernard O. Outcome in adulthood of biliary atresia: A study of 63 patients who survived for over 20 years with their native liver. Hepatology 2005;41:366-71.

18. Henkel AS, Buchman AL. Nutritional support in patients with chronic liver disease. Nat Clin Pract Gastroenterol Hepatol 2006;3:202-9.

19. Bu LN, Chen HL, Chang CJ, et al. Prophylactic oral antibiotics in prevention of recurrent cholangitis after the Kasai portoenterostomy. J Pediatr Surg 2003;38:590-3.

20. Wu ET, Chen HL, Ni YH, et al. Bacterial cholangitis in patients with biliary atresia: impact on short-term outcome. Pediatr Surg Int 2001;17:390-5.

21. Bu LN, Chen HL, Ni YH, et al. Multiple intrahepatic biliary cysts in children with biliary atresia. J Pediatr Surg 2002;37:1183-7.

22. Ling SC. Should children with esophageal varices receive betablockers for the primary prevention of variceal hemorrhage? Can J Gastroenterol 2005;19:661-6.

23. de Franchis R. Evolving consensus in portal hypertension. Report of the Baveno IV consensus workshop on methodology of diagnosis and therapy in portal hypertension. J Hepatol 2005;43:167-76.

24. Alagille D, Habib EC, Thomassin N. L'atresie des voies biliaires extrahepatiques permeables chez l'enfant. J Par Pediatr 1969:301-18. (Abst)

25. Alagille D, Estrada A, Hadchouel M, Gautier M, Odievre M, Dommergues JP. Syndromic paucity of interlobular bile ducts (Alagille syndrome or arteriohepatic dysplasia): Review of 80 cases. J Pediatr 1987;110:195-200.

26. Emerick KM, Rand EB, Goldmuntz E, Krantz ID, Spinner NB, Piccoli DA. Features of Alagille syndrome in 92 patients: Frequency and relation to prognosis. Hepatology 1999;29:822-9.

27. Bhadri VA, Stormon MO, Arbuckle S, Lam AH, Gaskin KJ, Shun A. Hepatocellular carcinoma in children with Alagille syndrome. J Pediatr Gastroenterol Nutr 2005;41:676-8.

28. Hoffenberg EJ, Narkewicz MR, Sondheimer JM, Smith DJ, Silverman A, Sokol RJ. Outcome of syndromic paucity of interlobular bile ducts (Alagille syndrome) with onset of cholestasis in infancy. J Pediatr 1995;127:220-4.

29. Berard E, Sarles J, Triolo V, et al. Renovascular hypertension and vascular anomalies in Alagille syndrome. Pediatr Nephrol 1998;12:121-4.

30. Schonck M, Hoorntje S, van Hooff J. Renal transplantation in Alagille syndrome. Nephrol Dial Transplant 1998;13:197-9. 
31. Emerick KM, Krantz ID, Kamath BM, et al. Intracranial vascular abnormalities in patients with Alagille syndrome. J Pediatr Gastroenterol Nutr 2005;41:99-107.

32. Kamath BM, Spinner NB, Emerick KM, et al. Vascular anomalies in Alagille syndrome: A significant cause of morbidity and mortality. Circulation 2004;109:1354-8.

33. Li L, Krantz ID, Deng Y, et al. Alagille syndrome is caused by mutations in human Jagged1, which encodes a ligand for Notch1. Nat Genet 1997;16:243-51.

34. Oda T, Elkahloun AG, Pike BL, et al. Mutations in the human Jagged1 gene are responsible for Alagille syndrome. Nat Genet 1997;16:235-42.

35. Harper JA, Yuan JS, Tan JB, Visan I, Guidos CJ. Notch signaling in development and disease. Clin Genet 2003;64:461-72.

36. Kamath BM, Bason L, Piccoli DA, Krantz ID, Spinner NB. Consequences of JAG1 mutations. J Med Genet 2003;40:891-5.

37. Duche M, Habes D, Lababidi A, Chardot C, Wenz J, Bernard O. Percutaneous endoscopic gastrostomy for continuous feeding in children with chronic cholestasis. J Pediatr Gastroenterol Nutr 1999;29:42-5

38. Mattei P, von Allmen D, Piccoli D, Rand E. Relief of intractable pruritis in Alagille syndrome by partial external biliary diversion. J Pediatr Surg 2006;41:104-7.

39. Lykavieris P, Hadchouel M, Chardot C, Bernard O. Outcome of liver disease in children with Alagille syndrome: A study of 163 patients. Gut 2001;49:431-5.

40. Englert C, Grabhorn E, Burdelski M, Ganschow R. Liver transplantation in children with Alagille syndrome: Indications and outcome. Pediatr Transplant 2006;10:154-8.

41. Ozcay F, Varan B, Tokel K, Cetin I, Dalgic A, Haberal M. Severe peripheral pulmonary artery stenosis is not a contraindication to liver transplantation in Alagille syndrome. Pediatr Transplant 2006;10:108-11.

42. Kasahara M, Kiuchi T, Inomata Y, et al. Living-related liver transplantation for Alagille syndrome. Transplantation 2003;75:2147-50.

43. Kerkar N, Norton K, Suchy FJ. The hepatic fibrocystic diseases. Clin Liver Dis 2006;10:55-71,v-vi.

44. Ward CJ, Hogan MC, Rossetti S, et al. The gene mutated in autosomal recessive polycystic kidney disease encodes a large, receptor-like protein. Nat Genet 2002;30:259-69.

45. Masyuk TV, Huang BQ, Ward CJ, et al. Defects in cholangiocyte fibrocystin expression and ciliary structure in the PCK rat. Gastroenterology 2003;125:1303-10.

46. Awasthi A, Das A, Srinivasan R, Joshi K. Morphological and immunohistochemical analysis of ductal plate malformation: Correlation with fetal liver. Histopathology 2004;45:260-7.

47. Guay-Woodford LM, Desmond RA. Autosomal recessive polycystic kidney disease: The clinical experience in North America. Pediatrics 2003;111:1072-80.

48. Fonck C, Chauveau D, Gagnadoux MF, Pirson Y, Grunfeld JP. Autosomal recessive polycystic kidney disease in adulthood. Nephrol Dial Transplant 2001;16:1648-52.

49. Adeva M, El-Youssef M, Rossetti S, et al. Clinical and molecular characterization defines a broadened spectrum of autosomal recessive polycystic kidney disease (ARPKD). Medicine (Baltimore) 2006;85:1-21.

50. Bockhorn M, Malago M, Lang $\mathrm{H}$, et al. The role of surgery in Caroli's disease. J Am Coll Surg 2006;202:928-32.

51. Davis ID, Ho M, Hupertz V, Avner ED. Survival of childhood polycystic kidney disease following renal transplantation: The impact of advanced hepatobiliary disease. Pediatr Transplant 2003;7:364-9.
52. Khan K, Schwarzenberg SJ, Sharp HL, Matas AJ, Chavers BM. Morbidity from congenital hepatic fibrosis after renal transplantation for autosomal recessive polycystic kidney disease. Am J Transplant 2002;2:360-5.

53. Clayton RJ, Iber FL, Ruebner BH, McKusick VA. Byler disease. Fatal familial intrahepatic cholestasis in an Amish kindred. Am J Dis Child 1969;117:112-24

54. Knisely AS. Progressive familial intrahepatic cholestasis: A personal perspective. Pediatr Dev Pathol 2000;3:113-25.

55. Thompson R, Strautnieks S. BSEP: Function and role in progressive familial intrahepatic cholestasis. Semin Liver Dis 2001;21:545-50.

56. Ujhazy P, Ortiz D, Misra S, et al. Familial intrahepatic cholestasis 1: Studies of localization and function. Hepatology 2001;34:768-75. (Erratum in 2002;35:246)

57. Whitington PF, Freese DK, Alonso EM, Schwarzenberg SJ, Sharp HL. Clinical and biochemical findings in progressive familial intrahepatic cholestasis. J Pediatr Gastroenterol Nutr 1994;18:134-41.

58. Knisely AS, Strautnieks SS, Meier Y, et al. Hepatocellular carcinoma in ten children under five years of age with bile salt export pump deficiency. Hepatology 2006;44:478-86.

59. Kurbegov AC, Setchell KD, Haas JE, et al. Biliary diversion for progressive familial intrahepatic cholestasis: Improved liver morphology and bile acid profile. Gastroenterology 2003; 125:1227-34

60. Ismail H, Kalicinski P, Markiewicz M, et al. Treatment of progressive familial intrahepatic cholestasis: Liver transplantation or partial external biliary diversion. Pediatr Transplant 1999;3:219-24.

61. Cutillo L, Najimi M, Smets F, et al. Safety of living-related liver transplantation for progressive familial intrahepatic cholestasis. Pediatr Transplant 2006;10:570-4.

62. Bull LN, van Eijk MJ, Pawlikowska L, et al. A gene encoding a P-type ATPase mutated in two forms of hereditary cholestasis. Nat Genet 1998;18:219-24.

63. van Mil SW, van der Woerd WL, van der Brugge G, et al. Benign recurrent intrahepatic cholestasis type 2 is caused by mutations in ABCB11. Gastroenterology 2004;127:379-84.

64. Poupon R. Intrahepatic cholestasis of pregnancy: From bedside to bench to bedside. Liver Int 2005;25:467-8.

65. Reyes H, Gonzalez MC, Ribalta J, et al. Prevalence of intrahepatic cholestasis of pregnancy in Chile. Ann Intern Med 1978;88:487-93.

66. Pauli-Magnus C, Lang T, Meier Y, et al. Sequence analysis of bile salt export pump (ABCB11) and multidrug resistance p-glycoprotein 3 (ABCB4, MDR3) in patients with intrahepatic cholestasis of pregnancy. Pharmacogenetics 2004;14:91-102.

67. Jacquemin E, De Vree JM, Cresteil D, et al. The wide spectrum of multidrug resistance 3 deficiency: From neonatal cholestasis to cirrhosis of adulthood. Gastroenterology 2001;120:1448-58.

68. Rosmorduc O, Hermelin B, Poupon R. MDR3 gene defect in adults with symptomatic intrahepatic and gallbladder cholesterol cholelithiasis. Gastroenterology 2001;120:1459-67.

69. Lucena JF, Herrero JI, Quiroga J, et al. A multidrug resistance 3 gene mutation causing cholelithiasis, cholestasis of pregnancy, and adulthood biliary cirrhosis. Gastroenterology 2003;124:1037-42.

70. Pauli-Magnus C, Kerb R, Fattinger K, et al. BSEP and MDR3 haplotype structure in healthy Caucasians, primary biliary cirrhosis and primary sclerosing cholangitis. Hepatology 2004;39:779-91.

71. Dahlan Y, Smith L, Simmonds D, et al. Pediatric-onset primary biliary cirrhosis. Gastroenterology 2003;125:1476-9. 


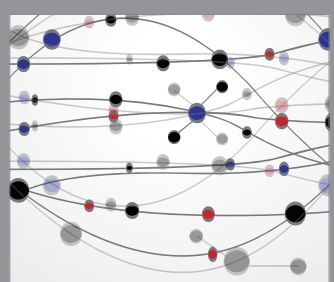

The Scientific World Journal
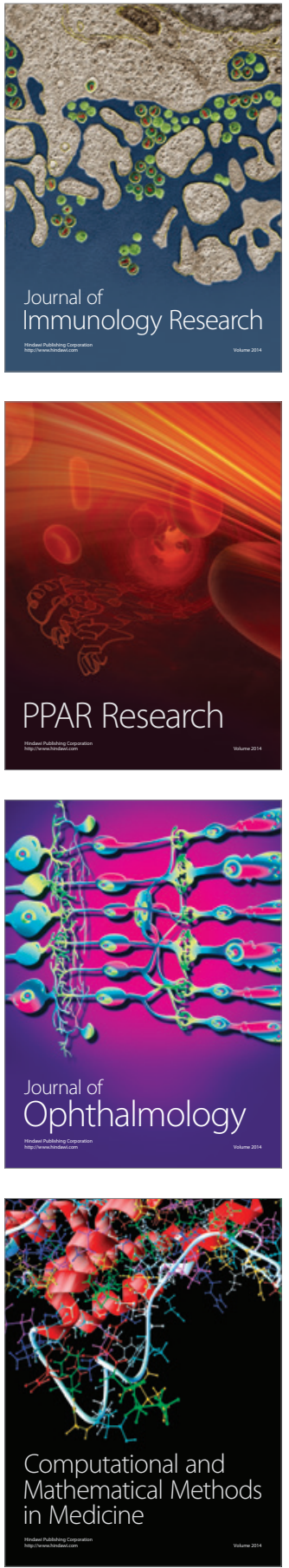

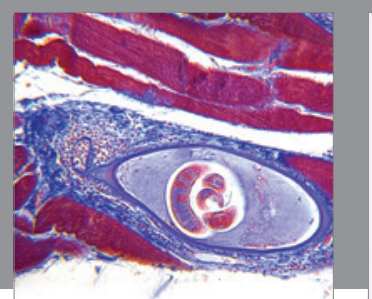

Gastroenterology Research and Practice

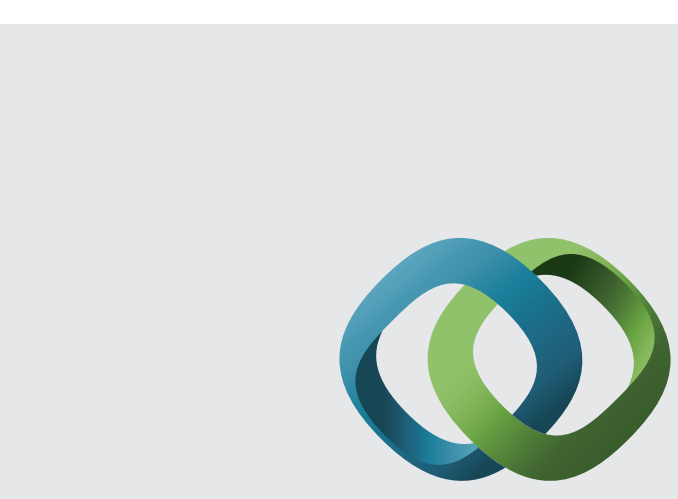

\section{Hindawi}

Submit your manuscripts at

http://www.hindawi.com
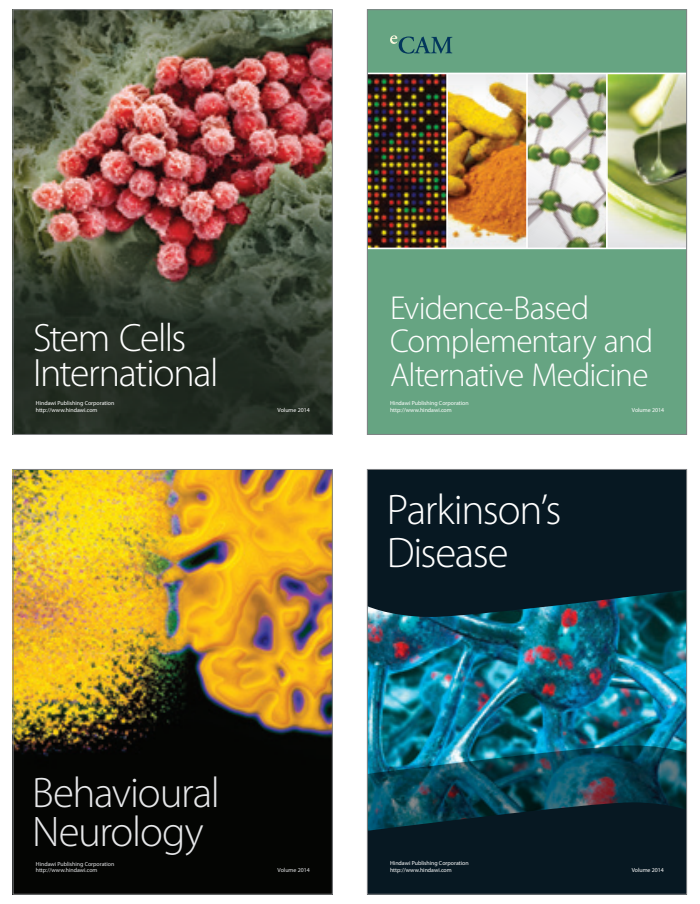
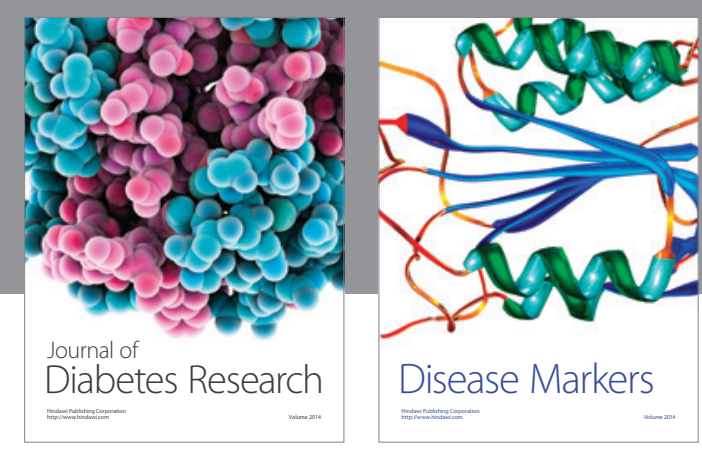

Disease Markers
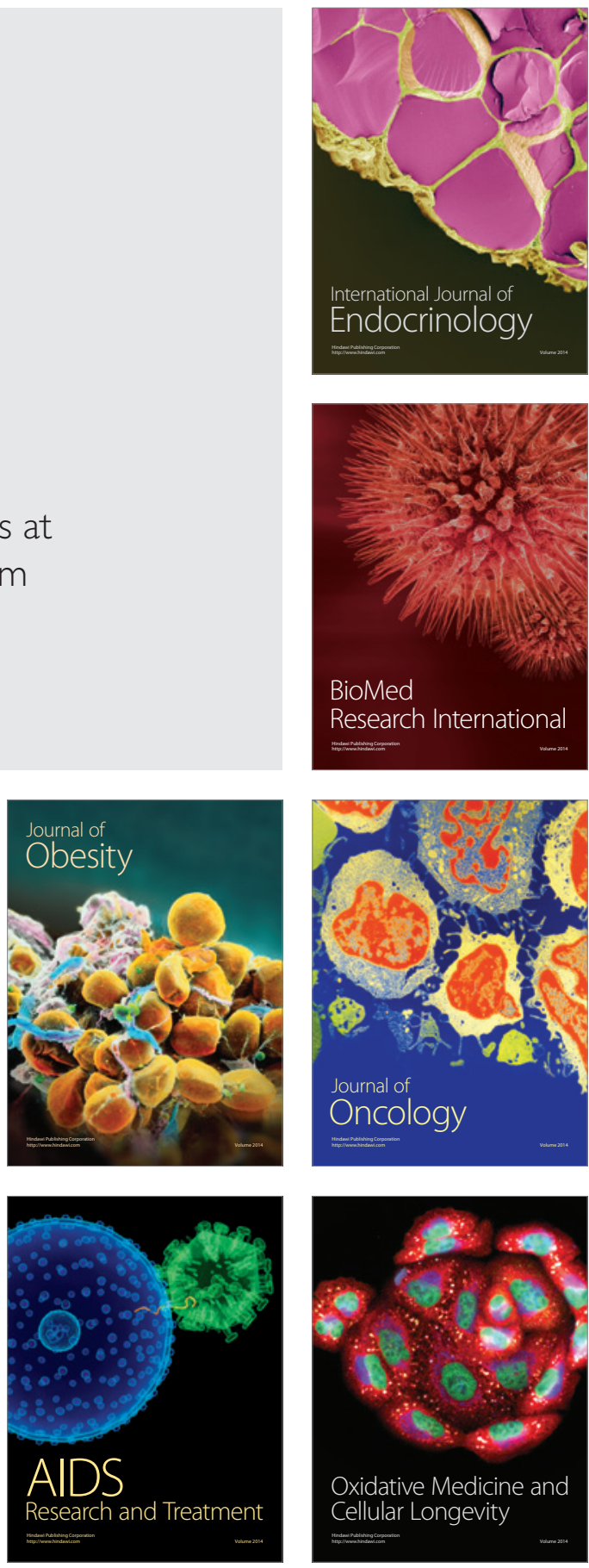